
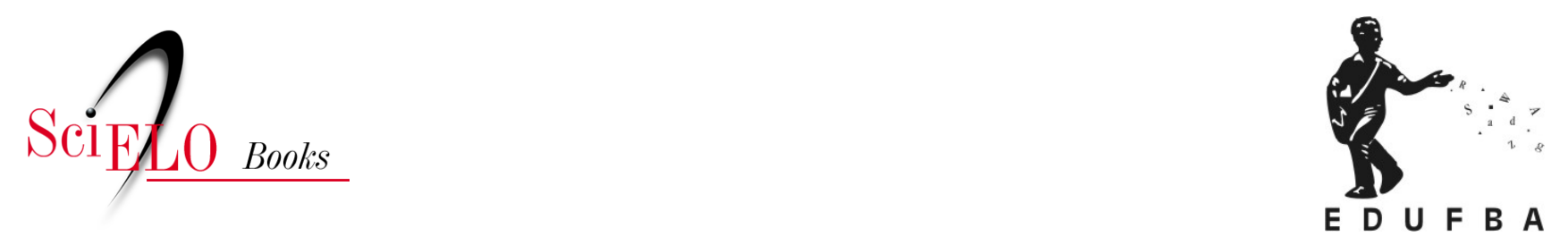

\title{
Tema 2 - Whatsapp e processos educativos Expansão e reconfigurações das práticas de leitura e escrita por meio do Whatsapp
}

\author{
Cristiane de Magalhães Porto \\ Kaio Eduardo de Jesus Oliveira \\ André Luiz Alves
}

\section{SciELO Books / SciELO Livros / SciELO Libros}

PORTO, C.M., OLIVEIRA, K.E.J., and ALVES, A.L. Expansão e reconfigurações das práticas de leitura e escrita por meio do Whatsapp. In: PORTO, C., OLIVEIRA, K.E., and CHAGAS, A., comp. Whatsapp e educação: entre mensagens, imagens e sons [online]. Salvador: Ilhéus: EDUFBA; EDITUS, 2017, pp. 113-128. ISBN 978-85-232-2020-4. https://doi.org/10.7476/9788523220204.0007. \section{International license.}

All the contents of this work, except where otherwise noted, is licensed under a Creative Commons Attribution 4.0

Todo o conteúdo deste trabalho, exceto quando houver ressalva, é publicado sob a licença Creative Commons Atribição $\underline{4.0}$. 


\title{
EXPANSÁO E RECONFIGURAÇÓES DAS PRÁTICAS DE LEITURA E ESCRITA POR MEIO DO WHATSAPP
}

\author{
Cristiane de Magalhães Porto - UNIT \\ Kaio Eduardo de Jesus Oliveira - UNIT \\ André Luiz Alves - UNIT
}

\section{Entrelaçamentos iniciais}

Ler significa aproximar-se de algo que acaba de ganhar existência. (CALVINO, 1999, p. 180).

Os resultados de 2015 do Programa Internacional de Avaliação de Alunos (PISA), que examina o desempenho escolar em mais de 60 países, entre eles o Brasil, suscitaram em debates e controvérsias em diferentes âmbitos. Os jornais The New York Times, o britânico Times Educational Supplement, o espanhol El País, por exemplo, discutiram de maneira crítica a situação do ensino médio de seus respectivos países à luz dos resultados do PISA.

No Brasil, a avaliação do Programa também foi tema de muito debate. $\mathrm{O}$ resultado mais preocupante, discutido pelos críticos, foi a estagnação do conhecimento dos adolescentes brasileiros em relação às avaliações anteriores. As médias dos alunos nas três áreas analisadas - matemática, ciências e leitura - praticamente estacionaram entre 2009 e 2015, deixando o Brasil nas últimas colocações da lista dos 69 países avaliados. 
Não entendendo claramente, o que lê, segundo o PISA, a maioria dos alunos brasileiros possui dificuldades para adquirir mais conhecimentos e, na concepção dos organizadores deste exame trienal, para exercer plenamente sua cidadania. Esses resultados refletem a realidade dos processos educativos do Brasil que se estabelece atualmente, caracterizando jovens e adultos escolarizados, mas sem conhecimentos básicos correspondentes ao seu grau de estudos, isto é, um conhecimento incapaz de auxiliá-los com suas próprias habilidades de leitura e a escrita para sua atividade social e profissional.

Não obstante, no cenário cultural estabelecido na Cibercultura, favorecido pela popularização do uso de Instant Messengers (Mensageiros Instantâneos), de redes sociais e dos dispositivos móveis em processos comunicativos; novos processos de leitura, escrita e de compreensão de textos têm se estabelecido como tarefa cotidiana. Tanto no Brasil, como em outros países, a generalização do uso de redes sociais e de aplicativos de mensagens instantâneas como o WhatsApp possibilita novas experiências nos processos de escrever e, principalmente, de ler. Cria assim um novo ambiente de autoria e produção de conteúdo permeado pela linguagem digital.

Por meio de aplicativos de mensagens instantâneas, como o WhatsApp, os processos comunicacionais e as práticas de leitura e escrita passam a ser constantes e constituídas por outras características e sentidos próprias da Cibercultura, organizadas pelo hipertexto, pela produção e compartilhamentos de áudios, vídeos e imagens. Essas características evidenciam uma nova prática de letramento, constituída por elementos e práticas que são próprios da cultura digital.

Podemos supor, assim, que as tecnologias de escrita, instrumentos das práticas de leitura e de escrita, desempenham um papel de organização e reorganização destes processos comunicativos e educativos. Lévy (1993) inclui as tecnologias de escrita entre as tecnologias intelectuais, responsáveis por gerar estilos de pensamento diferentes (observe-se o subtítulo de seu livro As tecnologias da inteligência: "o futuro do pensamento na era da informática”); esse 
autor insiste, porém, que as tecnologias intelectuais não determinam, mas condicionam processos cognitivos e discursivos.

Deste modo, o aplicativo WhatsApp, como mediador funcional de novas práticas de letramento social no processo comunicativo, possibilita reconfiguraçóes das habilidades de ler e escrever, que podem ser evidenciadas, entre outras questóes, a partir dos pontos básicos a seguir: $\mathrm{O}$ texto no papel é escrito e é lido linearmente, sequencialmente - da esquerda para a direita, de cima para baixo, uma página após a outra; já o texto no aplicativo - o hipertexto - é escrito e é lido de forma multilinear, de forma não sequencial, utilizando-se links ou rastros que vão trazendo telas numa reconfiguração de possibilidades, sem que haja uma ordem predefinida, ou uma relação direta com um único interlocutor.

A dimensáo do texto no papel é materialmente definida pelo autor: identifica-se claramente seu começo e seu fim, as páginas são numeradas, o que lhes atribui uma determinada posição numa ordem consecutiva. Enquanto o hipertexto produzido no WhatsApp tem a dimensão que o leitor lhe der: seu começo é onde o leitor escolhe, com um clique, a primeira tela, numa imagem, em um áudio ou vídeo; termina quando o leitor fecha o aplicativo ou ao finalizar o processo comunicativo com o interlocutor.

Mediante as questóes apresentadas até aqui, por meio de uma pesquisa bibliográfica, neste texto nos propomos discutir as reconfiguraçóes das habilidades e práticas de leitura e escrita no aplicativo WhatsApp. Assim, defendemos o argumento de que o app tem favorecido processos comunicativos por meio de mensagens instantâneas e possibilitado novas práticas de leitura e escrita. Este aspecto ressignifica estas habilidades, por meio de novos elementos próprios do aplicativo, do hipertexto e da cultura digital, como emojis, emoticons, áudios, vídeos e imagens.

Nas seçóes que seguem, buscaremos explorar a figura do leitor e escritor que na Cibercultura assumem as duas posiçóes, redimensionando os elementos da leitura e da escrita que caracte- 
rizam o processo comunicacional. Na seção seguinte, o WhatsApp, protagonista deste texto, será descrito, exploraremos suas potencialidades com o objetivo de informar como suas capacidades podem estabelecer novos formatos de leitura e escrita. Por fim, no último ponto, em meio à pesquisa bibliográfica, buscaremos enfatizar nosso argumento de que o WhatsApp favorece as novas e diversas práticas de leitura e escrita.

\section{O leitor escritor em tempos de Cibercultura}

Nosso mote para começar é "Penso que as palavras essenciais que me expressam se encontram nessas folhas que nem sabem quem sou” (BORGES, 2009). Assim, Jorge Luís Borges se expressa como homem de palavras que se perfaz entre criar e se expressar por meio destas. No entanto, elas não sabem quem ele é.

Pensarmos o leitor e o escritor na contemporaneidade passa um pouco pela mensagem contida no escrito do Borges, pois com o advento da Web 2.0 e com os dispositivos móveis em evidência, nos deparamos com uma nova relação entre emissor e receptor. $\mathrm{Ou}$ seja, percebemos que essas duas posiçóes se fundem e surge o "Interata”. Trata-se daquele que se assume como leitor e também autor, aquele que revela e busca desvelar as palavras, o ato de ler e escrever em um tempo contínuo. Não existe mais um receptor "passivo" e um emissor que prevalece. $\mathrm{Na}$ verdade, passou a existir uma interaçáo entre estes elementos e a mensagem, estes se entrelaçam e se projetam nesta nova forma de ler e escrever.

Sabemos que a interatividade permite a comunicação um-um e todos-todos, o conhecimento é construído interativamente entre o sujeito e o objeto a partir do momento que ele age e sofre uma ação do objeto, desenvolvendo assim a sua capacidade cognitiva. Isto é, o sujeito realiza a interação à medida que ele e o objeto se comunicam. Esta característica se aplica ao ato de ler e escrever. 
Os aplicativos conectados à internet tornaram-se um espaço plural, onde se produz e se publica textos que se sustentam não apenas nas palavras, mas nas imagens e, até mesmo, em sons. Santaella (2009) lança mão de um tipo de leitor que traz em sua prática fenômenos da Cibercultura. Trata-se do leitor ubíquo, aquele que lê e transita entre as formas, interaçóes de forças, movimentos, direçôes, traços e cores. Isto é, aquele que consegue imergir e submergir em meio às diversas direções proporçôes da nova maneira de ler e escrever na Cibercultura.

Por meio dos dispositivos móveis, à continuidade do tempo se soma a continuidade do espaço: a informaçáo é acessível de qualquer lugar. É para essa direçáo que aponta a evolução dos dispositivos móveis, atestada pelos celulares multifuncionais de última geração, a saber: tornar absolutamente ubíquos e pervasivos o acesso à informação, a comunicação e a aquisição de conhecimento. (SANTAELLA, 2013, p. 19).

Dessa forma, observamos que os artefatos que compóem este momento faz-nos deparar com a inovação das formas de ler e escrever. Não apenas a mudança de plataforma, mas o movimento de aprender em mobilidade, em múltiplos lugares e a qualquer instante. Um aplicativo como o WhatsApp é um dispositivo que propicia não apenas a mobilidade do usuário, mas o potencial transformador que este modelo híbrido de ler e escrever apresenta; nos desafiando a descobrir e articular novas formas de ler, escrever e aprender.

É importante salientarmos que, em tempo de conexão contínua, a escrita é fator essencial para a comunicaçáo na rede, mesmo estando integrada a imagens e sons. Tais aspectos configuram um hibridismo na maneira das pessoas se comunicarem e se relacionarem, tensionando relaçóes complexas entre o meio e o uso da linguagem.

As tecnologias contemporâneas, mais especificamente o aplicativo WhatsApp, reconfiguram as nossas relaçôes com os objetos e 
o uso que fazemos deles. O leitor-escritor do aplicativo é alguém que redimensiona o ato de ler e escrever, criando uma escrita mais participativa que se utiliza de imagens e sons para compor a mensagem.

Deparamo-nos, atualmente, com uma leitura e uma escrita como elementos principais da nossa vida social e cultural. A escrita contemporânea se reinventa por meio do uso de letras, símbolos, imagens e sons. Estes aspectos, em grande parte, marcam o modo de escrever, numa formulação de novas escritas, coadunando um acordo entre o contexto e a audiência.

Nesta cultura midiática o homem investiga e espera por conteúdos imersivos, a realidade aponta para uma transformação na maneira de consumir, usar e recriar a informação. Torna-se necessário fornecer instrumentos que, somados aos recursos disponíveis, permitam ao usuário uma experiência adequada à sua realidade tecnológica. Esses artefatos, a exemplo do WhatsApp, auxiliam na compreensão do mundo, por intermédio de experiências que estimulem seus sentidos, tornando-o partícipe no ato de enveredar pelo caminho da prática de ler, escrever e produzir novos textos e formatos.

É justamente neste mundo de polifonia e multiplicidade que se observamos um leitor com uma ação mais incisiva, ele abre máo da passividade que ainda poderia obstar a pluralidade desafiadora do texto e atua como um escritor em busca de um caminho onde o "reino das palavras" se configure, também, por meio de imagens e sons. A imagem das palavras fica como ato de comunicar e intercambiar ideias, pensando que as palavras estão aqui, mas elas ainda não nos explicam em essência.

\section{O WhatsApp e a ressignificaçáo dos processos comunicativos}

Na contemporaneidade, os processos comunicativos entre os sujeitos envolvidos no contexto educativo ganharam novos contornos. Estes podem ser mediados por dispositivos móveis e apli- 
cativos de mensagens instantâneas, como o WhatsApp Inc, no qual professores e alunos, ensinam e aprendem, simultaneamente - a partir de fluxos interacionais em espiral e colaborativos de construção de saberes.

Desse modo, o WhatsApp possibilita novas formas de interação, de autoria e de produção de conteúdo, assim como novas redes de transmissão de informaçóes; gerando transformaçóes nos processos comunicacionais, nos modos de ensinar e aprender, na prática de leitura e também de expressáo escrita.

Fundado em 2009 por Brian Acton e Jan Koum, na cidade estadunidense de Santa Clara, na Califórnia, a rapidez com que o WhatsApp se difundiu superou o crescimento do Facebook e fez com que Mark Zuckerberg, presidente e cofundador da rede social, comprasse, em fevereiro de 2014, o aplicativo por US\$ 19 bilhóes.

A popularidade do Instant Messenger já não é uma pauta nova para ninguém. $\mathrm{O}$ app de troca de mensagens está nas mãos de todo mundo há um bom tempo e não há dúvidas de que ele veio para ficar. Um estudo feito pela Opinion Box (2015), plataforma digital de pesquisa, indagou o seguinte: "Se você pudesse instalar um único Aplicativo no seu Smartphone, qual seria?”. O grande vitorioso foi o WhatsApp, escolhido por $56 \%$ das mulheres e $50 \%$ dos homens. Também foi o preferido pelos mais jovens: $45 \%$ dos respondentes com idades entre 16 e 29 anos o escolheriam, frente a 37\% das pessoas com 30 a 49 anos e $26 \%$ entre aqueles com 50 anos ou mais. Em segundo lugar ficou o Facebook.

WhatsApp é um trocadilho com What's $U p$ (E aí?). O site do desenvolvedor descreve-o como um $a p p^{1}$ (como é comumente chamado) multiplataforma que permite trocar mensagens instantâneas de texto (e multimídia) com o auxílio de dispositivos móveis

1 Um aplicativo ou aplicação móvel, conhecido normalmente por seu nome abreviado App, é desenvolvido para ser instalado em um dispositivo móvel (smartphone). Os apps têm o propósito de facilitar o dia a dia de seu utilizador, fornecendo-lhe as mais diversas funcionalidades com inúmeras possibilidades de uso. 
(smartphone, tablet, computador portátil etc.). Não há custo para enviar mensagens e ficar em contato com outros utilizadores que também possuam esta aplicação habilitada em seus dispositivos só é preciso estar conectado à internet (4G/3G/2G/EDGE ou WiFi quando disponível).

Além das mensagens básicas, os usuários deste mensageiro podem criar grupos, enviar mensagens ilimitadas com fotos, imagens, vídeos e áudios em tempo real - mediante uma interface moderna, agradável e fluida. Porque usar o WhatsApp como potencializador das práticas de leitura e escrita

$\mathrm{O}$ aplicativo do ícone verde funciona com um número telefônico e se integra perfeitamente com a agenda de contatos existente. Dessa forma, é possível criar Grupos que agregam contatos. Ao criar o Grupo, é permissível adicionar um avatar (foto da turma) na janela de conversas, nomeá-lo de maneira criativa (ambos editáveis pelos Administradores do Grupo: Professor e Líder de turma). Considera-se o perfil da classe, o componente curricular ou o conteúdo/atividade da vez e adiciona até 256 alunos-participantes. As interaçóes grupais acontecerão independente de o Professor salvar ou não todos os contatos dos alunos-participantes em sua agenda.

Figura 1 - Interaçáo grupal entre pares no WhatsApp

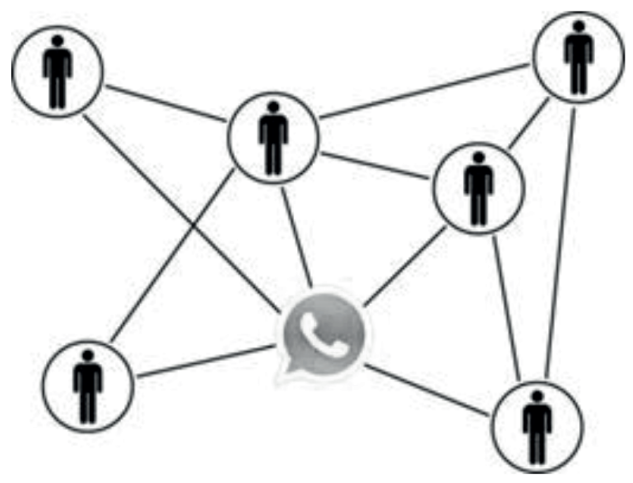

Fonte: Baixar WhatsApp (2017). 
Disponível em três versōes, o maior Messenger instantâneo do mundo pode ser acessado tanto no Smartphone (WhatsApp Messenger) como no Computador (WhatsApp Web ou WhatsApp Desktop). O WhatsApp Messenger é um aplicativo que pode ser "baixado" gratuitamente em Lojas de aplicativos como App Store e Google Play Store, por exemplo. Já as versões Web e Desktop para computadores permitem enviar e receber mensagens por meio do navegador de internet ou diretamente na máquina do utilizador, respectivamente. Por conseguinte, é o usuário quem decide como utilizar o app, uma vez que as três versóes funcionam exatamente do mesmo modo.

O WhatsApp permite desenhar, escrever e inserir emoticons/ emojis em fotos, imagens e vídeos, tornando os fluxos interacionais dinâmicos e descontraídos. Para isso, basta acessar a função da "Câmera" ou selecionar o arquivo nos álbuns/pastas do dispositivo móvel para edição, em seguida, anexá-lo a conversa.

Sem precisar anexá-lo a e-mails, o WhatsApp propicia enviar arquivos em PDF ou em ZIP, de até $100 \mathrm{MB}$, para os contatos, por meio da opção "Documento" no menu de compartilhamentos como também arquivos do Word, Excel e PowerPoint. No Grupo, basta o professor ou aluno-participante enviar arquivos em formatos diferenciados e, com um simples toque, fazer o download - facilitando o compartilhamento de anexos e enriquecendo a experiência de uso. Estes arquivos podem ser fotos, vídeos, documentos (nas extensôes citadas), localização, contato, entre outros.

É vantajoso, também, acessar o histórico de compartilhamentos de "Mídias" (imagem, áudio e vídeo), "Links" de sites diversos e "Documentos" enviados-recebidos nos fluxos interacionais por meio do menu "Dados do Grupo"; além do quantitativo de mensagens sinalizadas como favoritas. Em meio a tantas mensagens trocadas entre pares (professor-alunos, alunos-professor, alunos-alunos), estes conteúdos podem ser localizados com facilidade, enviados, automaticamente, para os álbuns/pastas do dispositivo 
móvel ou armazenados na rolagem de conversas. Portanto, basta clicar sobre o menu "Dados do Grupo" e selecionar qualquer uma das abas ("Mídia", "Documentos" ou "Links") para resgatar o conteúdo desejado.

Ainda em "Dados do Grupo", é possível silenciar o "assobio" inconfundível do "Zap Zap", personalizar o "toque de alerta", salvar as mídias recebidas no rolo da câmera, acessar a lista de participantes ("X de 256"), adicionar e convidar participantes para o Grupo via Link, limpar conversa e sair do Grupo. Já por intermédio da aba "Exportar Conversa”, o WhatsApp viabiliza o envio do histórico/ backup das mensagens de texto (em formato .txt) e multimídia dos fluxos interacionais por e-mail ou na nuvem - favorecendo o arquivamento de todas as informaçóes publicizadas no Grupo durante a conversação. Por outro lado, no rodapé deste menu, são registrados o iniciador, a data e o horário de criação do Grupo.

Recursos de texto riscado, negrito e itálico foram adicionados ao WhatsApp, permitindo que os pares personalizem o seu processo de escrita nos fluxos interacionais. Para enviar frases ou palavras riscadas, basta inserir o acento til $(-)$ no início e fim da frase ou palavra. Para ativar o negrito, usar o caractere asterisco $\left(^{*}\right)$ antes e depois da frase ou palavra. Caso queira aplicar o itálico na formatação, só acrescentar o underline (_) ao início e fim da frase ou palavra.

O Whats $A p p$ também admite alterar o estilo da letra utilizada na conversa. A fonte FixedSys remete à máquina de escrever, tem maior tamanho e espaço entre os caracteres e, por uma questão estética, poderá ser aproveitada para destacar alguma informação relevante do texto. Para usá-la, basta inserir três sinais de acento grave (' ') no começo e no final da frase. Vale ressaltar que, no transcorrer dos fluxos interacionais, é possível empregar vários tipos de formatação ao mesmo tempo; para isso, é só combinar os códigos.

Após liberar as formataçóes de texto, o app disponibilizou o recurso de citação, que possibilita responder a mensagens especí- 
ficas nas conversas em Grupo, inclusive, marcar o usuário a quem está se referindo. Assim, os pares poderão saber para qual mensagem (e interagente) a resposta foi direcionada. Para explorar esta funcionalidade, basta selecionar-pressionar a mensagem, clicar em "Responder" e depois enviar normalmente. Este recurso também é válido para as mídias compartilhadas durante os fluxos interacionais. Por outro lado, para citar alguém no Grupo, basta usar o símbolo arroba (@) antes de escrever o nome do utilizador e enviar a mensagem.

Outra função deste app é poder ter acesso aos detalhes de confirmação de envio (um tracinho cinza ou verde), entrega a visualização de uma determinada mensagem/arquivo mediante sinalização do indicador Double Check (checagem dupla) - ver quando e quantos alunos-participantes receberam (dois tracinhos cinzas ou verdes) e visualizaram (dois tracinhos azuis) o que foi compartilhado no Grupo - se habilitados nas configuraçóes de privacidade de cada usuário.

O campo status desta aplicação, junto à foto de perfil, é um indicador em tempo real do que se está fazendo ou pensando, mantendo os pares informados. Este, por sua vez, pode ser preenchido com frases pré-programadas do WhatsApp ("Disponível”, "Ocupado", "Em reuniáo" etc.) ou personalizado com frases de pensadores/ escritores, trechos de músicas e/ou emoticons/emojis, por exemplo. Agora chamado de "Recado", devido atualizaçáo mais recente, também é possível exibir no status; fotos, GIFs e vídeos que somem em 24 horas - semelhante à função "Stories" (Minhas Histórias) do Snapchat, Instagram e Facebook Messenger Day.

Outro recurso são marcadores que informam quando os interagentes estão "On-line", "Digitando" uma mensagem, "Gravando" um áudio e até a hora de seu último acesso: "Visto por Último"; se habilitado, individualmente, nas configuraçóes de privacidade. Outra característica do Instant Messenger é a pluralidade de emojis/emoticons - ícones ilustrativos usados nos fluxos intera- 
cionais que personalizam a comunicação e possibilitam incorporar elementos de humor, reações e sensações (modulaçóes no modo de enunciação).

Outra possibilidade interessante do "Uátzap" são as "Listas de Transmissóes" para enviar ou encaminhar, individualmente, mensagens de texto, vídeos, imagens e áudio para várias pessoas ao mesmo tempo.

A criptografia (em grego: kryptós, "escondido”, e gráphein, “escrita") ponta a ponta do WhatsApp é um fator importante de segurança que codifica as mensagens - sejam elas individuais ou em Grupos - para que somente o autor e o destinatário tenham acesso ao conteúdo e ao teor do que é trocado nos fluxos interacionais do aplicativo. Ou seja, durante a encriptação, o conteúdo das mensagens é transformado da sua forma original para outra ilegível; impedindo que ele seja interceptado por hackers, criminosos, incluindo o próprio WhatsApp.

O fenômeno que se tornou o WhatsApp Messenger já não surpreende ninguém. Segundo dados da pesquisa "Panorama Mobile Time/Opinion Box" (Abril/2016), o WhatsApp lidera o ranking dos Instant Messengers (Mensageiros Instantâneos) mais presentes na home screen dos brasileiros, lança novos recursos regularmente ${ }^{2} \mathrm{e}$ não há mais dúvida de que a concorrência tem um caminho bem longo para alcançá-lo.

Atentos à propagação deste aplicativo e de todas as mudanças sociais que ele tem provocado desde a sua criação - além de suas funcionalidades e possibilidades de uso elencadas acima - elegemos o WhatsApp como suporte e potencializador dos processos comunicacionais, dos modos de ensinar e aprender, das práticas de leitura e também de expressão escrita.

2 O WhatsApp é atualizado regularmente. Ao baixar a versão mais recente, é possível receber todos os recursos e melhorias disponíveis; como também, correções de bugs (erros). Logo, cabe ressaltar que estes pesquisadores exploraram algumas funcionalidades vigentes até a elaboração deste texto. 


\section{Observaçóes à guisa da conclusáo}

Neste texto, nos propomos a discutir as potencialidades e possibilidades do WhatsApp Messenger como mediador de outras práticas de letramento, escrita e leitura que se constroem no processo comunicativo e consequentemente educativo. Mediante estas inquietaçôes foi possível sustentar o argumento de que a comunicação e educação ubíqua possibilitada pelo WhatsApp oportunizam a elaboração de uma escrita permeada por novos elementos específicos da cultura digital.

Comumente, o texto no papel é escrito e lido de forma linear, sequencial, da esquerda para a direita, de cima para baixo, uma página após a outra; com a reconfiguração das habilidades de leitura e escrita no hipertexto e no suporte digital, outras possibilidades são erigidas. Assim, a comunicaçáo em aplicativos, a escrita e a leitura se configuram de forma multilinear, de maneira não sequencial. Utiliza-se de links ou rastros diversos que vão trazendo telas numa reconfiguração de possibilidades, sem que haja uma ordem predefinida ou uma sequência lógica dos acontecimentos. $\mathrm{Ou}$, ainda, uma relação direta com um único interlocutor.

Nesse contexto, o processo educativo por meio da escrita e leitura multilinear e não sequencial se articulam também mediante o descobrimento constante, em um modo de aprender permanente e ubíquo. Assim, o processo comunicativo mediado pelo WhatsApp é notável de serendipidade, ou seja, de buscas, pesquisas e de descobertas em uma reconfiguração da concepção de letramento que, agora, se reinventa com a inserção de sons, imagens e vídeos.

Em um simples clique, ou em vários cliques, pula-se livremente de uma página a outra, de um interlocutor para outro, viajando sem muita lógica, ou por uma lógica outra, desarticulada e rizomática, entre conteúdos discrepantes. Partimos, assim, de uma comunicação e escrita em um estilo próprio e tradicional, para um 
novo processo de leitura e de escrita com contextos e sentidos extremamente diferentes e inesperados.

Os Grupos do WhatsApp também são mais um recurso didático que podem ressignificar o processo de escrita e leitura. É uma prática que estamos desenvolvendo e aprendendo constantemente no uso cotidiano com a comunicaçáo com outros. Os usuários naturalmente se adequam aos critérios do processo de leitura e escrita grupal sejam com áudios, vídeos, imagens e textos.

As múltiplas formas de ler e escrever que nos proporciona o aplicativo WhatsApp são mais um motivo para repensarmos as nossas metodologias de ensino para leitura e a escrita na Cibercultura. Este aspecto faz surgir um novo estilo a leitura e a escrita se encontram nos fios dos mais diversos artefatos. Observamos a escrita, marcando seu espaço na internet, não apenas quantitativamente, mas, também, de maneira qualitativa. De acordo com Pinker (2016), os universitários estão escrevendo mais que gerações anteriores, não apenas utilizando símbolos, abreviaçóes e mensagens instantâneas, mas textos de boa qualidade.

Borges (1979), afirmou que "[...] o livro é outra coisa: o livro é extensão da memória e da imaginação". Podemos afirmar hoje que na Cibercultura nossa imaginação transborda as páginas dos livros e ganha forma em textos, imagens e sons. Tudo potencializado pela presença das tecnologias digitais e telemáticas no ciberespaço em um ecossistema que propicia a colaboração e o compartilhamento do ler e escrever entre letras, imagens e sons.

O Grupo do WhatsApp é mais um recurso didático. É uma prática que estamos desenvolvendo e aprendendo com ela. Nunca usamos a tecnologia desse jeito, então estamos achando ótimo. Os alunos estão aderindo aos pouco, mas todos que fazem parte dos grupos participam bem. Eles estão mais concentrados e conseguem entender melhor o que falamos nas aulas. A leitura facilitou muito a aprendizagem.

Por isso temos hoje significativas práticas de escrita e leitura via WhatsApp. Basta pensarmos nas práticas diárias de vários grupos 
criados no aplicativo onde são gerados comentários sobre aulas, livros lidos, situação política e econômica do País, entre outros. Este novo estilo de ler e produzir contorna os multidirecionamentos que usamos para ler os fenômenos da Cibercultura e como estes nos auxiliam em nosso cotidiano como leitor e produtor de textos e reflexóes.

\section{Referências}

BAIXAR WHATSAPP. Whatsappear. Disponível em: <http:// www.whatsappear.com.br/>. Acesso em: 13 jun. 2017.

BORGES, Jorge Luís. Oral. Buenos Aires: Emecé, 1979.

BORGES, Jorge Luís. Poesia. São Paulo: Companhia das Letras, 2009.

CALVINO, Ítalo. Se um viajante numa noite de inverno. São Paulo: Companhia das Letras, 1999.

COUTO, Edvaldo; PORTO, Cristiane; SANTOS, Edméa (Org.) App-Learning: experiências de pesquisa e formação. Salvador: Edufba, 2016.

PESQUISA Opinion Box. Disponível em: <http://zh.clicrbs.com. $\mathrm{br} / \mathrm{rs} /$ noticias/tecnologia/noticia/2015/05/whatsapp-e-o-apppreferido-dos-brasileiros-afirma-pesquisa-4765352.html>. Acesso em: 8 jun. 2017.

PESQUISA “Panorama Mobile Time/Opinion Box”. Disponível em: <https://revistapronews.wordpress.com/2016/06/28/ panorama-mobile-timeopinion-box-aponta-uso-de-apps-nobrasil-por-eles/>. Acesso em: 10 jun. 2017. 
PINKER, Steven. Guia de escrita: como conceber um texto com clareza, precisão e elegância. Trad. Rodolfo Ilari. São Paulo: Contexto, 2016.

PORTO, Cristiane et al. (Org.). Pesquisa e mobilidade na cibercultura: itinerâncias docentes. Salvador: EDUFBA, 2015.

SANTAELLA, Lucia. Comunicação ubíqua: repercussôes na cultura e na educação. São Paulo: Paulus, 2013. 